\title{
Wave Extremes in the North East Atlantic from Ensemble Forecasts
}

\author{
Øyvind Breivik $*$ Ole Johan Aarnes ${ }^{\S} \quad$ Jean-Raymond Bidlot ${ }^{\ddagger}$ \\ Ana Carrasco ${ }^{\S} \quad$ Øyvind Saetra ${ }^{\S}$
}

July 30, 2018

\begin{abstract}
A method for estimating return values from ensembles of forecasts at advanced lead times is presented. Return values of significant wave height in the North-East Atlantic, the Norwegian Sea and the North Sea are computed from archived +240 -h forecasts of the ECMWF ensemble prediction system (EPS) from 1999 to 2009.

We make three assumptions: First, each forecast is representative of a six-hour interval and collectively the data set is then comparable to a time period of 226 years. Second, the model climate matches the observed distribution, which we confirm by comparing with buoy data. Third, the ensemble members are sufficiently uncorrelated to be considered independent realizations of the model climate. We find anomaly correlations of 0.20 , but peak events $\left(>P_{97}\right)$ are entirely uncorrelated. By comparing return values from individual members with return values of subsamples of the data set we also find that the estimates follow the same distribution and appear unaffected by correlations in the ensemble. The annual mean and variance over the 11-year archived period exhibit no significant departures from stationarity compared with a recent reforecast, i.e., there is no spurious trend due to model upgrades.

EPS yields significantly higher return values than ERA-40 and ERA-Interim and is in good agreement with the high-resolution hindcast NORA10, except in the lee of unresolved islands where EPS overestimates and in enclosed seas where it is biased low. Confidence intervals are half the width of those found for ERA-Interim due to the magnitude of the data set.
\end{abstract}

${ }^{*}$ Final version published as Breivik, $\varnothing$, O J Aarnes, J-R Bidlot, A Carrasco and Ø Saetra (2013). Wave Extremes in the North East Atlantic from Ensemble Forecasts, J Climate, doi:10.1175/JCLI-D-12-00738.1 (in press)

${ }^{\dagger}$ Corresponding author. E-mail: oyvind.breivik@ecmwf.int

${ }_{\ddagger}^{\ddagger}$ European Centre for Medium-Range Weather Forecasts (ECMWF), Shinfield Park, Reading, RG2 9AX, United Kingdom

$\S$ Norwegian Meteorological Institute 


\section{Introduction}

Extreme value estimates of atmospheric and oceanographic variables are usually derived from observational records or from model reconstructions of the past (reanalyses and hindcasts).

A given probability of exceedance or equivalently return period corresponds to a return value of the geophysical variable in question. This return value is normally approximated by fitting the Generalized Extreme Value (GEV) distribution to blocked maxima (such as annual maxima) or by fitting the Generalized Pareto (GP) distribution to exceedances above a threshold, see Smith (1990) and Coles (2001). In the atmospheric and oceanographic sciences 100-year return values are usually sought (Lopatoukhin et al., 2000), which means that observational or modeled time series are rarely long enough to cover the return period, even for the longest reanalyses and hindcasts (see Uppala et al. 2005; Kalnay et al. 1996; Wang et al. 2012 for descriptions of some recent reanalyses). Extrapolation of the parametric fit to lower probabilities of exceedance (return periods longer than the observational record or modeled time series) is then required. This affects the confidence intervals of the return value estimates and is a concern when using shorter records like altimeter measurements (Alves and Young, 2003; Young et al., 2011). Model or observational bias will further increase the confidence intervals, but is much harder to identify than the unsystematic error stemming from insufficient length of the time series.

Trends and low-frequency oscillations can seriously influence return value estimates from time series. This can be handled using non-stationary techniques (see Coles 2001, Chapter 6 for an introduction). Due to imminent climate change (IPCC, 2007), estimating return values from time series with trends has recently received some attention in the earth sciences. Kharin and Zwiers (2000) and Kharin and Zwiers (2005) investigated the impact of a linear trend on the GEV distribution of the annual extremes while Parey et al. (2007) looked at extending the extreme value theory to assess the return values of temperature extremes in the presence of a linear trend over a 54-year period for French observing stations. de Winter et al. (2012) investigated the changing wave extremes in a regional climate projection of the North Sea for the time-slice 2071-2100. Similarly, Wang et al. (2004) and Wang and Swail (2006) investigated the impact of changing wave climate on wave extremes in the span of the 21st century using statistical projections and coupled climate models.

Even if non-stationarity can be handled it raises the question of what exactly the return value estimates are to be used for. If a probability of exceedance valid for a certain time period is required, similar to what Kharin and Zwiers 2000 did for 21-year time slices from climate projections considered sufficiently stationary, then a long time series is not necessarily of much interest. What is then needed is an estimate of exceedance levels for that given time slice. Such a repository of possible weather realizations does in fact exist. The ensemble prediction system (EPS) operated by the European Centre for Medium-Range Weather Forecasts (ECMWF) has now been in operation for 20 years (Molteni et al., 1996; Buizza et al., 2007; Hagedorn et al., 2008). The individual ensemble members start from almost identical initial conditions with only small perturbations added to the best guess analysis (Buizza et al., 1999; Leutbecher and Palmer, 2008) to spread the ensemble in a way representative of the uncertainty of the forecast system. 
Although there is considerable forecast skill after a lead time of five days (Richardson, 2010), the skill drops rapidly after day six, and on day 10 the individual members are only weakly correlated with each other and with observations, as we will show in Sec 2 . If the quantiles of the entire cumulative distribution of the ensemble compare well with observations then the forecasts can be considered random realizations of a realistic model climate.

Return values for significant wave height have been estimated from a wide variety of data sources in the past, ranging from relatively short observational records (Batties 1972 and Muir and El-Shaarawi 1986), satellite altimeters (Cooper and Forristall, 1997; Alves and Young, 2003; Vinoth and Young, 2011), long-term global reanalyses (Caires and Sterl, 2005a; Sterl and Caires, 2005), regional model hindcasts (Wang and Swail, 2001, 2002; Weisse and Günther, 2007; Aarnes et al., 2012), and statistical downscaling (Breivik et al., 2009). Here we explore a new approach to estimating return values of significant wave height using ensemble forecasts at advanced lead times instead of a time series. A similar approach has been explored by Van den Brink et al. (2005) for the special case of river flooding protection using seasonal forecast ensembles from ECMWF's earlier System 2 Seasonal Forecast System (Anderson et al., 2003). Van den Brink et al. (2005) employed the entire seasonal forecasts from a lead time of one month up to six months, arguing that the modelled North Atlantic Oscillation (NAO) was only weakly correlated with observed NAO after one month, dropping further to essentially zero for the subsequent months. We employ a different approach where we instead extract the significant wave height for a fixed forecast time $(+240 \mathrm{~h})$ from the EPS version of the Integrated Forecast System (IFS) of ECMWF. We have gathered all forecasts at $+240 \mathrm{~h}$ generated during the period 1999-2009, equivalent (as will be explained in Sec 2) to $\sim 226$ years if the data had formed a continuous time series. As will be explained in Sec 3 we assume that each forecast represents a six-hour interval, which is a reasonable assumption for a coarse model and analogous to the temporal resolution of traditional reanalyses. However, this also means that we estimate return values of the six-hourly average sea state. We address this in Sec 3 and discuss the implications further in Sec 5 .

The method to be explored allows us to utilize a vast unused resource of climate realizations and their lack of skill is actually a prerequisite since extreme value theory demands that events be uncorrelated. However, there are important caveats to the interpretation and use of the method. First, climate trends are by construct not captured by the method since we base our estimates on a time-slice of $\sim 10$ years. Likewise, quasicyclical phenomena like El Niño with a period longer than what is covered by the archive may influence the results. This suggests the following use and interpretation of EPS return values: If probabilities of exceedance for the present time period are sought, then the ensemble data set is superior since it is not affected by long-term trends and lowfrequency cycles. If on the other hand long-term return values are required then techniques for estimating extremes from time series with trends must be considered (see Kharin and Zwiers 2000, 2005; Parey et al. 2007), or at least comparison with traditional time series covering a sufficiently long period.

The paper is organized as follows. Sec 2 presents the observational records and the reanalysis and hindcast data sets used to test the method. Sec 3 presents the method used to compute return values from forecast ensembles at long lead times and how it differs from traditional return value estimates from observational records and modeled 
time series. We then investigate the independence of ensemble members and the climatology of the archived forecasts by comparing against a model climatology from a recent reforecast (see Hagedorn et al. 2012) and observations. Sec 4 compares the return values found from the EPS with three reference model data sets, namely the reanalyses ERA-40 and ERA-Interim (ERA-I hereafter) and a high-resolution regional hindcast for the Norwegian Sea and adjacent seas, NORA10 (see Reistad et al. 2011; Aarnes et al. 2012). Sec5 discusses the differences in method and results, and points at possible weaknesses of the method. Finally, Sec 6 presents our conclusions on the general usefulness of the method and its application to significant wave height and the ECMWF EPS system.

\section{Modelled and Observed Wave Climate}

To assess the validity of our return value estimates from EPS forecasts, we will make a number of comparisons with observational records, reanalyses and hindcasts of significant wave height. This section presents the observations used and the five model data sets (ERA-40, ERA-I, NORA10, EPS and EPS reforecasts). We investigate the EPS climatology at analysis time (labeled EPS0) and at +240-h lead time (labeled EPS240) and assess the stationarity and independence of EPS240. Time series of all model data have been interpolated to buoy locations.

Time series have been extracted from ERA-40, ERA-I, NORA10 and EPS and interpolated to the same $1^{\circ} \times 1^{\circ}$ grid of the northeastern part of the Atlantic Ocean, the North Sea and the Norwegian Sea in order to make geographical comparisons of extreme value estimates. The regridding and interpolation will inevitably smooth the field slightly. This will influence the return values somewhat. It is of interest to compare our EPS return estimates with these reference data sets because all three archives (ERA-40, ERA-I and NORA10) are frequently used for return value estimation (see e.g. Caires and Sterl 2005a; Aarnes et al. 2012).

\section{$2.1 \quad$ ERA-40}

Significant wave height from the ERA-40 reanalysis (Uppala et al., 2005) is available for the period September 1957 to August 2002 on six-hourly temporal resolution. The atmospheric model was coupled to a deep-water version of the wave model (WAM) through exchange of a wave-modified Charnock parameter Janssen et al. 2002 and Ianssen 2004 pp 232-234). WAM was run on a regular $1.5^{\circ}$-grid. At this resolution the Shetland and Faroe archipelagoes are not resolved and the modeled wave field on the lee side of these islands is consequently biased high. It is also well known that ERA-40 is biased low in general (Caires and Sterl, 2005b; Reistad et al., 2011). For this study we have not attempted any correction either to the time series themselves, which is how Caires and Sterl (2005b) came up with the corrected semi-global fields referred to as the Corrected ERA-40, or by correction of the 100-year return values, which is how Caires and Sterl (2005a) and Sterl and Caires (2005) constructed the global maps of return values from ERA-40. We argue that for this study it is better to compare the original data sets to avoid confounding artefacts of the new approach with artefacts of the statistical correction algorithms employed by Caires and Sterl (2005a) and Caires and Sterl 
(2005b). However, we do discuss how our results qualitatively correspond to the results of Caires and Sterl (2005a) in Sec4.

\subsection{ERA-Interim}

ERA-I is a continually updated coupled atmosphere-wave reanalysis which originally covered the period from 1989 (roughly co-incident with the satellite era), but which has recently been extended back to 1979 (Simmons et al., 2007; Uppala et al., 2008; Dee et al., 2011). The resolution is $1.0^{\circ}$ for the wave model at the equator, but the resolution is kept nearly constant towards the poles by the use of an irregular latitude-longitude grid. The wave model is coupled to the atmospheric model in the same fashion as outlined above for ERA-40, but the ERA-I wave model physics include shallow-water effects important in areas like the southern North Sea. ERA-I also differs from ERA-40 in its use of a four-dimensional variational assimilation scheme and a substantially larger amount of observations, especially after 1991. ERA-I uses a subgrid scheme to represent the downstream impact of unresolved islands (Bidlot, 2012). Though a clear improvement over ERA-40, the wave field in the lee of the Faroes and the Shetland Isles is still biased a little high.

\subsection{The NORA10 regional hindcast}

NORA10, a recently completed atmospheric downscaling of ERA-40 and wave model hindcast on 10-11 km resolution, is described by Reistad et al. (2011). The model domain covers the North Sea, the Norwegian Sea and the Barent Sea. The temporal resolution of the archived fields is three hours. The hindcast initially covered the ERA-40 period (September 1957 to August 2002), but an extension with boundary and initial fields from the ECMWF IFS has since been added. The hindcast archive is continually updated. The breach of stationarity due to the change in boundary and initial values after August 2002 was investigated by Aarnes et al. (2012) and no statistically significant changes were found. The median and upper percentiles of NORA10 $H_{\mathrm{s}}$ show little bias and generally close correspondence with the wave observations used in this study. The model resolves the main coastal features and the archipelagoes in the Norwegian Sea. Like ERA-I the wave model is run in shallow water mode.

\subsection{ECMWF EPS archive}

We have extracted the significant wave height from archived operational ECMWF EPS wave forecasts for the period 1999-2009, a total of 11 years. The data set is not homogeneous, i.e., the resolution and the model physics of the operational EPS forecast system have been continually upgraded (see Fig 1 for the most important changes affecting the wave field). The wave model has been coupled to the atmospheric model in the same fashion as for ERA-I. The data assimilation scheme has been upgraded several times during the archived period, and the amount of data entering the assimilation cycle has steadily increased. It is also important to note that the forecast systems started issuing two forecasts per day on 2003-03-25 (00 and 12 UTC analysis time). This means that the amount of data is not uniform over the period. We have extracted the analysis and 
the +240 -h forecasts from the 50 perturbed ensemble members plus the control member (forced by unperturbed wind fields). We have also extracted the forecasts at $+228 \mathrm{~h}$ (EPS228 hereafter). This data set is naturally slightly more correlated than EPS240 and is used here primarily to assess the validity of the method.

\subsection{EPS reforecasts}

Since 2008 every new model cycle of the EPS has been accompanied by a model climatology based on reforecasting a five-member ensemble of the current model cycle (four perturbed and one unperturbed member) from ERA-I initial conditions every Thursday from 18 years back and up until the present day (Hagedorn et al., 2008; Hagedorn, 2008; Hagedorn et al., 2012; Prates and Buizza, 2011). These reforecasts are run to 32 days, similar to the operational forecasts. We have extracted the reforecasts valid at $+240 \mathrm{~h}$ from model cycle Cy36r4, in operation after the end of the archived period, from 60 locations in the north-east Atlantic, the Norwegian Sea and the North Sea. The reforecasts are in principle also useful for extreme value analysis, but unfortunately the data set is too small by two orders of magnitude to allow the kind of analysis attempted with the EPS forecasts:

$$
\frac{5 \text { weekly members } \times 18 \mathrm{yr}}{51 \text { members } \times 2 \text { daily forecasts } \times 7 \text { weekdays } \times 11 \mathrm{yr}} \approx 0.011 .
$$

\subsection{Comparing observed and modeled significant wave height}

Wave observations are routinely archived and quality-controlled by ECMWF as part of the wave model intercomparison effort (Bidlot et al., 2002). To make the observations comparable with model output Bidlot et al. (2002) averaged observations over four hours centered on the synoptic times. The rationale behind this averaging procedure is as follows. Typical wind conditions in the open ocean are on the order of $10 \mathrm{~m} \mathrm{~s}^{-1}$. For fully developed wind sea the group speed, which dictates the propagation speed across the model grid, will be comparable to the wind speed (Holthuijsen, 2007; World Meteorological Organization, 1998). If the resolution is $\sim 1.5^{\circ}$ then the time interval that is represented by the model output is 4-6 h. Archived model values, although "instantaneous" in the sense that they are model output, are thus slowly changing and should be considered averages representative of intervals of 4-6 $\mathrm{h}$ in the case of the coarser archives discussed below (ERA-40, ERA-I and EPS). The NORA10 archive has much higher resolution (10-11 km) and is consequently also archived at three-hourly resolution. Both ERA-40 and ERA-I are archived on six-hourly resolution and the return values derived from these reanalyses should be interpreted as six-hourly averages of the significant wave height. EPS is of comparable resolution and we assign the same interval to the EPS240 forecasts. We discuss this further in Sec5.

Three locations with quite different wave climate were selected from a total of 60 observation stations in the North East Atlantic, The Norwegian Sea and the North Sea for inspection of the relative performance of the reanalyses and the EPS:

- P40 (Ekofisk oil field, WMO code LF5U, $56.50^{\circ} \mathrm{N}, 003.20^{\circ}$ E) in the central North Sea 
- P35 (Heidrun oil field, WMO LF3N, 65.30 $\mathrm{N}, 007.30^{\circ} \mathrm{E}$ ) in the eastern Norwegian Sea

- B16 (K5 buoy, WMO 64045, 59.10 N, 011.40 W) in the north-east Atlantic

\section{Estimating return values from ensemble forecasts}

\subsection{Extreme value distributions applied to ensemble forecasts}

The two most commonly used statistical methods for estimating return values are based on the GEV distribution for blocked maxima and the GP distribution for values exceeding a set threshold. For completeness we repeat here the general form of the GEV and the GP distributions but refer to Coles (2001) for a more in-depth discussion. The GEV distribution (GEVD) is an asymptotic limit for a distribution of blocked maxima $M_{n}=\max \left\{X_{1}, X_{2}, \ldots, X_{n}\right\}$. The method is routinely used to approximate the probability distribution of blocked maxima such as annual maxima (Coles 2001, pp 45-51). However, the method can also be used on ensembles of independent and identically distributed (iid) forecasts since the blocking procedure itself makes no assumption of the grouping other than to ensure that all blocks have the same statistical properties. The blocking can thus be performed in many ways, but it is natural to block by ensemble member or some subset of time and member which is sufficiently large to ensure that the GEVD is a reasonably good approximation to the parent distribution. Following Coles (2001) the cumulative distribution function (CDF) of the block maxima formed from a random sequence of independent variables can be written

$$
G(z)=\exp \left\{-\left[1+\xi\left(\frac{z-\mu_{n}}{\sigma_{n}}\right)\right]^{-1 / \xi}\right\},
$$

where $\sigma_{n}$ is the scale parameter, $\mu_{n}$ is known as the location parameter, and $\xi$ is the so-called shape parameter. The GEV distribution contains as special cases the Fréchet $(\xi>0)$, Gumbel $(\xi=0)$ and reversed Weibull $(\xi<0)$ distributions. The width of confidence intervals will depend strongly on the sign of the shape parameter Hosking, 1984; Coles, 2001).

The GP method retains only values exceeding a threshold $u$. The transformed variable is written $y=X_{i}-u, y>0$. It can be shown (Coles 2001, pp 75-77) that the GP distribution (GPD) is applicable if the data $y$ are independent and the maxima $M_{n}$ formed from the original variable belong to the GEV distribution, Eq (2). The GDP is written

$$
H(y)=1-\left(1+{\frac{\xi y^{-1 / \xi}}{\tilde{\sigma}}}^{-}\right) .
$$

Here $\tilde{\sigma}=\sigma+\xi(u-\mu)$ and $\xi$ is the shape parameter found in Eq (2). For $\xi=0$ GP becomes an exponential distribution. In traditional studies of wind and wave extremes it is common to select only peaks separated by at least 24-48 hours to ensure that the maxima represent individual storm events (Lopatoukhin et al., 2000; Aarnes et al., 2012; Naess and Clausen, 2001). This is known as the "Peaks-over-threshold" method (POT) and it is the method we apply to the ERA-40, ERA-I and NORA10 time series. Since we assume (see below) that the EPS forecasts are uncorrelated at $+240 \mathrm{~h}$ the ensemble mem- 
bers represent independent events and we can retain all values exceeding the chosen threshold. In this case the return values are more properly referred to as GP threshold estimates rather than GP/POT estimates.

\subsection{Criteria for using ensembles for extreme value estimation}

The following assumptions must be shown to hold in order to estimate return values from ensemble forecasts:

1. Each forecast is representative of a time interval (e.g. six hours)

2. The model climatology distribution is comparable to the observed climatology distribution

3. No spurious trend in the mean and the variance due to model updates

4. No significant correlation between ensemble members at advanced lead times

If these conditions are met the ensemble can be assumed to be independent and identically distributed and representative of the observed wave climate. We will address each of these conditions below.

\subsubsection{Estimating return periods from ensembles}

Turning $M$ ensemble forecasts with $N$ ensemble members each into the equivalent of a time period is necessary in order to convert from probability of exceedance to a return period. We assume each forecast to represent a six-hour interval based on the following reasoning. First, $\Delta t=6 \mathrm{~h}$ matches the temporal resolution of the ERA-I and ERA-40 archives, simplifying the comparison. Second, as discussed in Sec 22.6), model fields are smoothly varying in time, making them representative of averages over typically 4-6 hours at the resolution of ERA-40, ERA-I and EPS. This allows us to treat the collection of ensemble forecasts as an equivalent time period $T_{\mathrm{eq}}=M N \Delta t$. We discuss the validity of this assumption in Sec5.

\subsubsection{Climatology of ensemble forecasts at advanced lead times}

To convince ourselves that the EPS240 dataset is identically distributed we need only look at the quantile-quantile (QQ) distribution of two members. Panel (c) of Fig 2 clearly demonstrates the similarity of the distributions of two randomly selected ensemble members (the statistics look essentially the same for all combinations of members, not shown). The QQ-plot against observations in panel (a) of Fig 2 makes it clear that the ensemble members at $+240 \mathrm{~h}$ represent the observed climate well. In fact, the cumulative distribution of the ensemble at $+240 \mathrm{~h}$ is somewhat better aligned with observations than at analysis time as can be seen in panel (b) of Fig 2 for the Ekofisk location in the North Sea, but the differences in distribution are small from analysis time to $+240 \mathrm{~h}$ for all the observation locations and we conclude that we can assume that the ensemble members are identically distributed and that they represent the observed wave climate well.

\subsubsection{Stationarity of model climate}

To address the question of whether there is a spurious trend in the model climate over the archived period we compare against the reforecasts for the same period from Cy36r4. We 
are only interested in the behavior of the $+240 \mathrm{~h}$ forecasts as our objective is to investigate whether the changes in model physics and resolution, especially in the early days of the EPS forecast system, will have significant impact on our return value estimates.

The EPS forecasts at lead time $+240 \mathrm{~h}$ are compared with the reforecasts at the same lead time and at the same analysis dates over the period 1999-2009 in Fig [3. Panel (a) presents the time series of the annual mean deviations of the significant wave height at 60 locations in the north-east Atlantic, the North Sea and the Norwegian Sea. The annual mean difference in their standard deviation is shown in panel (b). It is clear from the boxplots that there is considerable deviation in both mean and standard deviation between the EPS forecasts and the EPS reforecasts throughout the model domain from one year to another, but there is no consistent drift in either statistic. However, it is clear that the reforecasts have slightly higher mean $(\sim 0.05 \mathrm{~m})$ and standard deviation $(\sim 0.10 \mathrm{~m})$.

\subsubsection{Independence of ensemble forecasts at advanced lead times}

The motivation for using ensemble forecasts at long lead times is the anticipation that the upper percentile of the data will be found to be independent. In other words, we are looking for forecasts with as little skill as possible (Wilks, 2006). With a set of ensemble forecasts at advanced lead time (e.g. 240 hours), the question is then whether the correlation between two arbitrary ensemble members is sufficiently low for the members to be assumed independent. The residual correlation (after subtraction of the seasonal mean) between two fields can be investigated through the centered anomaly correlation (Wilks 2006, pp 311-312) which for two ensemble members $i$ and $j$ can be defined as

$$
r_{\mathrm{ACC}}=\frac{\operatorname{Cov}\left(x_{i}^{\prime}, x_{j}^{\prime}\right)}{s^{\prime 2}}
$$

where primes indicate centered anomalies. The anomaly correlation at all three locations is approximately 0.20 , while the actual correlation varies from 0.46 in the open ocean (B16 and P35) to 0.35 at Ekofisk (P40) in the central North Sea. With small variations this is the level of anomaly correlations found throughout the domain studied here.

Even weak correlations between ensemble members (if significant) may have a deleterious effect on the equivalent or effective ensemble size. This is a well known problem often discussed in the context of autocorrelated time series (von Storch and Zwiers 1999, pp 371-372). Denote the sample size (in our case the number of archived forecasts) $M$ and the ensemble size $N$. The entire ensemble is $X \in \mathbb{R}^{M \times N}$. The ensemble variancecovariance matrix is written $\left\langle e_{i} e_{j}\right\rangle \in \mathbb{R}^{N \times N}$, where $e_{i}$ represent departures from the ensemble mean. If we assume all members to have equal variance $\left\langle e_{i} e_{i}\right\rangle=s^{2}$ and common correlation $r$ (a reasonable assumption since there is nothing to distinguish one member from another) such that $\left\langle e_{i} e_{j}\right\rangle=r s^{2}$ (where we note that $r \equiv 1$ when $i=j$ ) we arrive at the following relation for the variance of the ensemble mean,

$$
s_{\bar{x}}^{2}=\frac{s^{2}}{N}(1+(N-1) r) .
$$

The effective sample size is now found from $s_{\bar{x}}^{2}=s^{2} / N^{*}$, i.e., the variance of the mean of a smaller ensemble of uncorrelated members should equal that of our correlated ensemble. 
The effective ensemble size becomes

$$
N^{*}=\frac{N}{1+(N-1) r}
$$

and it is clear that even quite weak correlations can seriously reduce the effective ensemble size and have a detrimental impact on the mean properties of the ensemble. However, assessing the impact of correlations on the ensemble mean alone is of limited value since only the upper percentiles of the data set are actually used for the return value estimates. To investigate the possible impact of correlations on the tail of the data set we first computed the correlation and the Spearman rank correlation (see Press et al. 1992) for a subset of the forecasts where at least one ensemble member exceeded the 97 percentile $\left(P_{97}\right)$. Members not exceeding the threshold were set to zero. The average rank correlation and Pearson's correlation coefficients were 0.05 for this subset of forecasts. This shows that the higher percentiles of the ensemble tend to be uncorrelated even if the ensemble itself exhibits weak correlation. This is not surprising given the nature of our analysis. We are selecting the upper percentiles from a large data set. This means that we are only selecting storm events, which are transient and fast-moving. It is unlikely that storm events exceeding $P_{97}$ will occur simultaneously in many ensemble members after a 10-day integration. Average sea state will on the other hand be more correlated at long lead times since such weather patterns are less transient (e.g., high pressure situations).

To assess the impact of any residual correlation on the return values we followed a heuristic approach suggested by M. Leutbecher (pers comm) where return values from $N$ individual ensemble members are compared with return values from decimated subsets of similar sample size where all members are used, but only every $N$-th forecast. We thus arrive at two distributions of return values drawn from samples of the same size $M$. Splitting the total data set in $N$ parts obviously increases the uncertainty associated with the return value estimates, but we are only interested in comparing the distributions of the two sets of return values. Fig 4 compares quantiles of the 51 member-wise return values (first axis) with the 51 return values from the decimated samples for location P40 in the central North Sea. It is evident that the two distributions are very similar with only slightly higher standard deviation $(1.83 \mathrm{~m} \mathrm{v} 1.67 \mathrm{~m})$ for the member-wise estimates. The average is practically the same $(11.30 \mathrm{~m})$. We conclude that the weak correlations found between ensemble members in the mean have no discernible impact on the expected value or the spread of the return estimates.

\section{Comparison of extreme value estimates and their confidence intervals}

Gridded estimates of the 100-year return value $H_{100}$ of the significant wave height were made from EPS240 interpolated to a $1.0^{\circ}$ grid for the North Atlantic, the Norwegian Sea and the North Sea using both blocked maxima (GEV) and threshold exceedances (GP). Note that this is an extraction procedure and does not reflect the underlying model resolution, which as Fig 1 shows has increased over the archived period. Ice-infested locations, i.e., locations where the modeled ice concentration ever exceeds $30 \%$, have been removed from the analysis. 
We start by looking at the differences we can expect from the existing reanalyses and hindcasts available to us. Fig 5 shows the difference between return values estimated from ERA-40 and ERA-I (panel a) and similarly between ERA-40 and NORA10 (panel b) using GP (POT) with a threshold of 97\%. The differences between ERA-40 and ERA-I (panel a) are moderate in the open ocean, $\sim 1 \mathrm{~m}$, but the enhanced resolution of ERA-I is clearly visible on the lee side of the Faroe and Shetland archipelagos. Also, ERA-40 yields higher estimates in the central North Sea due to the deep-water physics scheme employed by the ERA-40 WAM model. Panel (b) shows the difference between ERA-40 and NORA10. As reported earlier by Aarnes et al. (2012), NORA10 consistently estimates higher return values than ERA-40 (3-4 m higher in the northern North Atlantic), except along the open boundary to the south and west where the model is forced with ERA-40 boundary values. Note also that the central North Sea exhibits the smallest difference, since the ERA-40 deep-water physics yields higher values here. Reistad et al. (2011) looked at the upper percentiles of the NORA10 wave height distribution in a number of locations in the North Sea and the Norwegian Sea and found good agreement with buoy measurements. It is clear that the differences seen around the Faroes and Shetland in Fig 5 are due to resolution issues partly solved by ERA-I and more fully resolved by NORA10. In the open ocean ERA-40 and ERA-I seem to be in agreement while NORA10 estimates significantly higher return values (on the order of 3-4 $\mathrm{m}$ in the northern North Atlantic, consistent with what is found by Aarnes et al. 2012).

Fig 6 presents the return values for EPS240 using GEV (panel a) and GP (panel b). The differences are very small. The blocking for GEV was performed per ensemble member to minimize the effect of the varying resolution and the numerous model upgrades introduced throughout the archived period (cf Fig 1). The GP threshold was set at $P_{97}$, but varying this threshold did not affect the return values considerably (results not shown). Caires and Sterl (2005a) and Sterl and Caires (2005) find that ERA-40 when calibrated against buoy data yields return values on the order of $24 \mathrm{~m}$ in the northern North Atlantic; higher but much closer to our findings than the uncorrected ERA-40 return values.

Fig7 presents the difference between the GP 100-year return values found for EPS240 and those found for ERA-I (left panel) and NORA10 (right panel) using GP with a $P_{97}$ threshold. It is clear that EPS240 predicts considerably higher return values than what is found for ERA-I. The differences approach $5 \mathrm{~m}$ in the North Atlantic, and throughout the Norwegian Sea we see differences on the order of 2-3 $\mathrm{m}$. The differences between NORA10 and EPS240 are smaller (panel b), but here we see significant differences throughout the domain that must be considered separately. First, the influence of ERA40 on NORA10 is visible along the open boundary in the south-west, so the boundary zone should not be taken into account in this analysis. Second, EPS240 does not properly resolve the Faroes and the Shetland archipelagos. The middle North Sea is biased low, which is probably also a resolution issue. Away from these areas we see that the agreement is generally good, except in the northern part of the Norwegian Sea, where EPS240 is up to 3 m lower than the NORA10 estimates. Aarnes et al. (2012) discusses the large impact of an individual storm event on the NORA10 estimates in this area and we note that the confidence intervals are exceptionally wide here (14-22 m, see Aarnes et al. 2012, Fig 3). 


\subsection{Bootstrapping confidence intervals}

The GEV shape parameter $\xi$ in Eq (2) and its counterpart for GPD in Eq (3) determine the width of confidence intervals (Hosking, 1984; Coles, 2001). The significant wave height from the NORA10 hindcast has been shown by Aarnes et al. (2012) to exhibit a wide range of extreme value shape parameters within the Norwegian Sea and the adjacent seas with correspondingly varied confidence intervals.

We have estimated confidence intervals for EPS240 and ERA-I using a bootstrapping technique similar to that employed by Aarnes et al. (2012). For ERA-I which represents a traditional time series we have made 100 random draws with replacement from the POT data (see Fig 7). In the case of EPS240, we have similarly made random draws from the tail of the dataset exceeding the 97 percentile (note that this is technically not peaks-over-threshold since the EPS240 data are considered independent.

The upper limits of the confidence intervals found for ERA-I and EPS240 are shown in Fig 8 panels (a) and (b). The differences are pronounced. First, the confidence interval is much tighter for EPS240 (panel d), ranging from less than $1 \mathrm{~m}$ in the sheltered parts of the North Sea to approximately $2 \mathrm{~m}$ in the open ocean (relative width $5-10 \%$ of the return values). ERA-I (panels a and c) has confidence intervals up to $5 \mathrm{~m}$ (relative width $30 \%$ of the return values) in the north-east Atlantic. Second, the spatial variability of the confidence intervals is very low for EPS240, while the ERA-I intervals vary substantially throughout the domain due to sensitivity to individual storm events.

It is important to stress that even though the confidence intervals become much tighter with a larger data set, the bootstrapping method does not account for model bias. The bias must be assessed by comparing the observed and modeled wave height distributions, see Sec 3(3.2). We discuss the impact of model bias further in Sec5.

\section{Strengths and limitations to the method}

Estimating return values from ensembles at advanced lead times is a new technique, and the assumptions underlying the method have been outlined in Sec 3 . Here we discuss some of the perceived weaknesses of the method in general and how applicable the method appears to be for significant wave height. The main caveats to be aware of when using the technique on archived EPS forecasts in general are:

1. Spurious trends caused by model upgrades

2. Upper-percentile biases

3. Conversion to an equivalent time period

4. Correlations within the ensemble

5. Return value estimates in a changing climate

Although we do not find evidence of any spurious trend in the mean and the variance of the significant wave height at $+240 \mathrm{~h}$ (see Fig 3), we are aware that the IFS model updates over the past decade have led to an apparent increase in the 10-m wind speed at analysis time. S. Abdalla (pers comm) quantified this effect at analysis time to be about $29 \mathrm{~cm} \mathrm{~s}^{-1}$, i.e., the earlier analyses were biased low. The wave height will be somewhat affected by this, but it is thought to have a small effect on the extremes of waves found at advanced 
lead times, especially since some of the removed bias stems from changes to the data assimilation and will fade as the model integration becomes dynamically balanced at advanced lead times. The effect is also evident from inspection of Fig 2 where the wave height at analysis time (panel b) is seen to be biased low. Since this bias disappears for EPS240 (panel a), we believe that the model updates have had only a modest impact on the wave climatology at advanced lead times.

We have investigated the robustness of the return value estimates by also looking at EPS228. We select the maximum from each pair of EPS228 and EPS240 since the +228 and $+240-\mathrm{h}$ forecasts are strongly correlated (see Fig 9). This combined data set is now assumed equivalent to $2 \times 226$ years. The combined 100 -year GP return value estimates (indicated by blue circles) fall between the 100-year return values from the the two data sets (EPS228, green circles, and EPS240, red circles), which is what we expect when going to larger data sets. This suggests that even larger data sets may be built by selecting maxima from longer forecast sequences. However, care must be taken to avoid getting too close to the beginning of the forecast where the ensemble members are correlated.

We have also looked at the possible sources of bias to the extremes from EPS forecasts. Such a bias can not be estimated from a bootstrap procedure. Instead we have compared the return values of the ERA-40, ERA-I and EPS240 against NORA10 which has been shown to represent the upper percentiles well (Reistad et al., 2011; Aarnes et al., 2012). Biases can enter a model data set in two distinct ways. The first is through poor representation of physical processes. For example (as pointed out by Aarnes et al. 2012), ERA40 applies deep-water physics in areas where this is questionable (such as the southern North Sea). If a bias is due to poor model physics or poor model resolution then the bias should also be different from one region to another. The second way biases can enter a data set is through poor spatial and temporal sampling of the model fields. For example, both ERA-40 and ERA-I are archived with six-hourly resolution and will consequently miss some modeled storm maxima, even if a coarse model as discussed in Sec 2(2.6) is slowly varying and representative of significant wave height averaged over $6 \mathrm{~h}$. The data sets are also typically interpolated in space, leading to further reduction of extremes. This means that the return values from EPS and coarse resolution reanalyses such as ERA-40 and ERA-I should be interpreted as return values of the six-hourly average sea state, as discussed in Sec 2(2.6), and will thus generally be lower than those found from a high-resolution hindcast such as NORA10 where the model values represent shorter time intervals. Fig 10 shows how the return values ranging from $H_{1}, \ldots, H_{100}$ line up. It is clear that ERA-40 and ERA-I due to their negative bias give significantly lower return values than NORA10, especially in the open-ocean conditions in the North Atlantic (panel b). EPS240 on the other hand matches the return values better, and the shorter return periods also line up well here. For Ekofisk (panel a) in the central North Sea the situation is different. Here the shorter return periods match well, but due to the relatively coarse resolution of EPS240 $\mathrm{H}_{100}$ seems to converge to approximately the same value as ERA-40 and ERA-I (11.3 m). NORA10 yields 100-year return values closer to $13 \mathrm{~m}$ for this location. It seems likely that the EPS240 return values are biased low in enclosed seas and should consequently be used with some care in such areas. The EPS240 return values are close to NORA10 estimates in the open ocean and we conclude that the bias from spatial and temporal interpolation is of less importance, since otherwise the return values should be depressed everywhere. 
Lack of forecast skill at advanced lead times is an important requirement since the ensemble members must be assumed uncorrelated to be considered independent draws from the model climate. We have shown that the weak correlations in the mean are not present in the tail of the distribution in the case of significant wave height (see Sec 3). However, it seems likely that the method is not equally applicable to the investigation of the extremal behavior of parameters representing large-scale features, e.g. the North Atlantic Oscillation (NAO) index (Hurrell, 1995), or long-term (seasonal, say) averages. Here we do expect the ensemble forecast system to retain skill at advanced lead times, and indeed forecast skill in reproducing large-scale features is the rationale behind seasonal forecast systems (Stockdale et al., 1998, 2011), where the lead time typically goes to six months (Van den Brink et al., 2005). We therefore find it prudent to advice against employing the method on large-scale spatial averages or long-term temporal averages. It is also clear that the forecasts only differ from the initial conditions by as much as 240-h integrations allow and will still be influenced by the slow components of the earth system, like the Arctic ice cover. This means that for parameters influenced by climate change or where quasi-cyclical phenomena with long-periodic components such as the El Niño, Southern Oscillation (ENSO) are present we must be careful when assessing the return values since we must be convinced that the archive covers a sufficiently long period to capture all the stages of the phenomenon. As noted in Sec 1, under such circumstances non-stationary techniques employed on traditional time series and climate projections will be more relevant. If on the other hand return values valid for the present period are sought then ensemble forecasts are superior.

\section{Conclusion}

Return values estimated from long lead-time ensemble forecasts have been investigated and found to yield good results. The immediate advantage is clear; a huge data set of forecasts are readily available from the ECMWF archive. The method yields return values of significant wave height that are comparable to what is found from NORA10 but significantly higher than what is found from ERA-I and ERA-40. This result was not totally unexpected since it is known that ERA-I and especially ERA-40 tend to underestimate the upper percentiles of the wave height distribution. The EPS estimates are probably too low in enclosed seas (see Fig 10). Although we have only investigated the extremes in the North Atlantic, the North Sea and the Norwegian Sea, it appears likely that the extreme value estimates found from ERA-40 and ERA-I are too low globally (as discussed by Caires and Sterl 2005a; Sterl and Caires 2005 in the case of ERA-40). However, the return value estimates from NORA10 (Aarnes et al., 2012) and the present findings suggest that the corrected ERA-40 return estimates reported by Caires and Sterl (2005a) and Sterl and Caires (2005) are too high.

Return value estimation from large ensembles at advanced lead times is a general method which should be applicable to a wide range of atmospheric and oceanographic variables if the conditions discussed in Sec 3 and Sec 5 are met. It is clear that the EPS archive represents an unused resource which complements and perhaps yields more precise return values than traditional reanalyses and hindcasts. 


\section{Acknowledgment}

This work has been supported by the Research Council of Norway through the project "Wave Ensemble Prediction for Offshore Operations" (WEPO, grant no 200641) and through the European Union FP7 project MyWave (grant no 284455). This study has also been part of a PhD program partially funded by the Norwegian Centre for Offshore Wind Energy (NORCOWE) for OJA. The Norwegian Deepwater Programme (NDP) financed the construction of the NORA10 hindcast archive. The patient advice of Saleh Abdalla, Peter Janssen, Hans Hersbach and Martin Leutbecher is greatly appreciated. We would also like to thank the three anonymous reviewers. Their constructive comments helped improve the manuscript. 


\section{References}

Aarnes, O. J., Breivik, Ø., Reistad, M., 2012. Wave Extremes in the Northeast Atlantic. J Climate 25, 1529-1543, doi:10.1175/JCLI-D-11-00132.1, 10/bvbr7k.

Alves, J. H. G., Young, I. R., 2003. On estimating extreme wave heights using combined Geosat, Topex/Poseidon and ERS-1 altimeter data. Appl Ocean Res 25 (4), 167-186, doi:10.1016/j.apor.2004.01.002.

Anderson, D., Stockdale, T., Balmaseda, M., Ferranti, L., Vitart, F., Doblas-Reyes, R., Hagedorn, R., Jung, T., Vidard, A., Palmer, T., 2003. Comparison of the ECMWF seasonal forecast System 1 and 2, including the relative performance for the 1997/98 El Nino. ECMWF Technical Memoranda 404, European Centre for Medium-Range Weather Forecasts.

Battjes, J., 1972. Long-term wave height distributions at seven stations around the British Isles. Deutsch Hydrogr Z 25 (4), 179-189, doi:10.1007/BF02312702.

Bidlot, J., Holmes, D., Wittmann, P., Lalbeharry, R., Chen, H., 2002. Intercomparison of the performance of operational ocean wave forecasting systems with buoy data. Weather and Forecasting 17 (2), 287-310, doi:10.1175/15200434(2002)017<0287:IOTPOO > 2.0.CO;2.

Bidlot, J.-R., 2012. Present status of wave forecasting at ECMWF. In: Workshop on Ocean Waves, 25-27 June 2012. Available online at http://www.ecmwf.int/publications/. p. 15.

Breivik, Ø., Gusdal, Y., Furevik, B. R., Aarnes, O. J., Reistad, M., 2009. Nearshore wave forecasting and hindcasting by dynamical and statistical downscaling. J Marine Syst 78 (2), S235-S243, doi:10.1016/j.jmarsys.2009.01.025, doi:10/cbgwqd, arXiv:1206.3055.

Buizza, R., Bidlot, J.-R., Wedi, N., Fuentes, M., Hamrud, M., Holt, G., Vitart, F., 2007. The new ECMWF VAREPS (Variable Resolution Ensemble Prediction System). Q J R Meteorol Soc 133 (624), 681-695, doi:10.1002/qj.75.

Buizza, R., Milleer, M., Palmer, T. N., 1999. Stochastic representation of model uncertainties in the ECMWF ensemble prediction system. Q J R Meteorol Soc 125 (560), 2887-2908, doi:10.1002/qj.49712556006.

Caires, S., Sterl, A., 2005a. 100-year return value estimates for ocean wind speed and significant wave height from the ERA-40 data. Journal of Climate 18 (7), 1032-1048, doi:10.1175/JCLI-3312.1.

Caires, S., Sterl, A., 2005b. A new nonparametric method to correct model data: application to significant wave height from the ERA-40 re-analysis. Journal of Atmospheric and Oceanic Technology 22 (4), 443-459, doi:10.1175/JTECH1707.1.

Coles, S., 2001. An introduction to statistical modeling of extreme values. Springer Verlag. 
Cooper, C., Forristall, G., 1997. The use of satellite altimeter data to estimate the extreme wave climate. J Atmos Ocean Tech 14 (2), 254-266, doi:10.1175/15200426(1997)014<0254:TUOSAD>2.0.CO;2.

de Winter, R., Sterl, A., de Vries, J., Weber, S., Ruessink, G., 2012. The effect of climate change on extreme waves in front of the Dutch coast. Ocean Dynam 62 (8), 1139-1152, doi:10.1007/s10236-012-0551-7.

Dee, D., Uppala, S., Simmons, A., Berrisford, P., Poli, P., Kobayashi, S., Andrae, U., Balmaseda, M., Balsamo, G., Bauer, P., P, B., Beljaars, A., van de Berg, L., Bidlot, J., Bormann, N., et al., 2011. The ERA-Interim reanalysis: Configuration and performance of the data assimilation system. Q J R Meteorol Soc 137 (656), 553-597, doi:10.1002/qj.828.

Hagedorn, R., 2008. Using the ECMWF reforecast dataset to calibrate EPS forecasts. ECMWF newsletter, European Centre for Medium-Range Weather Forecasts.

Hagedorn, R., Buizza, R., Hamill, T., Leutbecher, M., Palmer, T., 2012. Comparing TIGGE multimodel forecasts with reforecast-calibrated ECMWF ensemble forecasts. QJ R Meteorol Soc, 14, doi:10.1002/qj.1895.

Hagedorn, R., Hamill, T., Whitaker, J., 2008. Probabilistic forecast calibration using ECMWF and GFS ensemble reforecasts. Part I: Two-meter temperatures. Mon Wea Rev 136 (7), 2608-2619, DOI:10.1175/2007MWR2411.1.

Holthuijsen, L., 2007. Waves in Oceanic and Coastal Waters. Cambridge University Press.

Hosking, J., 1984. Testing whether the shape parameter is zero in the generalized extreme-value distribution. Biometrika 71 (2), 367-374, doi:10.1093/biomet/71.2.367.

Hurrell, J. W., 1995. Decadal trends in the North Atlantic Oscillation: regional temperatures and precipitation. Science 269, 676-679, doi:10.1126/science.269.5224.676.

IPCC, 2007. Climate change 2007 - The physical science basis. Working Group I Contribution to the Fourth Assessment Report of the IPCC. Cambridge University Press.

Janssen, P., 2004. The interaction of ocean waves and wind. Cambridge University Press, Cambridge, UK.

Janssen, P., Doyle, J., Bidlot, J., Hansen, B., Isaksen, L., Viterbo, P., 2002. Impact and feedback of ocean waves on the atmosphere. Advances in Fluid Mechanics 33, 155197.

Kalnay, E., Kanamitsu, M., Kistler, R., Collins, W., Deaven, D., Gandin, L., Iredell, M., Saha, S., White, G., Woollen, J., et al., 1996. The NCEP/NCAR 40-Year Reanalysis Project. Bull Am Meteor Soc 77, 437-472, doi:10.1175/15200477(1996)077<0437:TNYRP>2.0.CO;2.

Kharin, V., Zwiers, F., 2000. Changes in the extremes in an ensemble of transient climate simulations with a coupled atmosphere-ocean GCM. Journal of Climate 13 (21), 37603788, doi:10.1175/1520-0442(2000)013<3760:CITEIA > 2.0.CO;2. 
Kharin, V., Zwiers, F., 2005. Estimating extremes in transient climate change simulations. Journal of Climate 18 (8), 1156-1173, doi:10.1175/JCLI3320.1.

Leutbecher, M., Palmer, T., 2008. Ensemble forecasting. Journal of Computational Physics 227 (7), 3515-3539, doi:10.1016/j.jcp.2007.02.014.

Lopatoukhin, L., Rozhkov, V., Ryabinin, V., Swail, V., Boukhanovsky, A., Degtyarev, A., 2000. Estimation of extreme wind wave heights. Tech. Rep. JCOMM Technical Report No 9, World Meteorological Organization.

Molteni, F., Buizza, R., Palmer, T. N., Petroliagis, T., 1996. The ECMWF ensemble prediction system: methodology and validation. Q J R Meteorol Soc 122 (529), 73-119, doi:10.1002/qj.49712252905.

Muir, L. R., El-Shaarawi, A., 1986. On the calculation of extreme wave heights: A review. Ocean Engng 13 (1), 93-118, doi:10.1016/0029-8018(86)90006-5.

Naess, A., Clausen, P., 2001. Combination of the Peaks-over-treshold and bootstrapping methods for extreme value prediction. Structural Safety 23, 315-330.

Parey, S., Malek, F., Laurent, C., Dacunha-Castelle, D., 2007. Trends and climate evolution: Statistical approach for very high temperatures in France. Climatic Change 81, 331-352, doi:10.1007/s10584-006-9116-4.

Prates, F., Buizza, R., 2011. PRET, the Probability of RETurn: a new probabilistic product based on generalized extreme-value theory. Q J R Meteorol Soc 137 (655), 521-537, doi:10.1002/qj.759.

Press, W. H., Teukolsky, S. A., Vetterling, W. T., Flannery, B. P., 1992. Numerical Recipes in FORTRAN, 2nd edition. Cambridge University Press, Cambridge.

Reistad, M., Breivik, Ø., Haakenstad, H., Aarnes, O. J., Furevik, B. R., Bidlot, J.-R., 2011. A high-resolution hindcast of wind and waves for the North Sea, the Norwegian Sea, and the Barents Sea. J Geophys Res 116, 1-18, C05019, doi:10.1029/2010JC006402, doi:10/fmnr2m, arXiv:1111.0770.

Richardson, D., 2010. Landmark in forecast performance. ECMWF newsletter, European Centre for Medium-Range Weather Forecasts.

Simmons, A., Uppala, S., Dee, D., Kobayashi, S., 2007. ERA-Interim: New ECMWF reanalysis products from 1989 onwards. ECMWF newsletter 110, 25-35.

Smith, R., 1990. Extreme value theory. In: Ledermann, E., Lloyd, E., Vajda, S., Alexander, C. (Eds.), Handbook of Applicable Mathematics. Wiley, pp. 437-471.

Sterl, A., Caires, S., 2005. Climatology, variability and extrema of ocean waves: the Webbased KNMI/ERA-40 wave atlas. International Journal of Climatology 25 (7), 963-977, doi:10.1002/joc.1175.

Stockdale, T., Anderson, D., Alves, J., Balmaseda, M., 1998. Global seasonal rainfall forecasts using a coupled ocean-atmosphere model. Nature 392 (6674), 370-373, doi:10.1038/32861. 
Stockdale, T., Anderson, D., Balmaseda, M., Doblas-Reyes, F., Ferranti, L., Mogensen, K., Palmer, T., Molteni, F., Vitart, F., 2011. ECMWF seasonal forecast system 3 and its prediction of sea surface temperature. Climate dynamics, 455-471, doi:10.1007/s00382010-0947-3.

Uppala, S., Dee, D., Kobayashi, S., Berrisford, P., Simmons, A., 2008. Towards a climate data assimilation system: Status update of ERA-Interim. Ecmwf newsletter, European Centre for Medium-Range Weather Forecasts.

Uppala, S., Kållberg, P., Simmons, A., et al., 2005. The ERA-40 Re-analysis. Q J R Meteorol Soc 131, 2961-3012, doi:10.1256/qj.04.176.

Van den Brink, H., Können, G., Opsteegh, J., Van Oldenborgh, G., Burgers, G., 2005. Estimating return periods of extreme events from ECMWF seasonal forecast ensembles. International Journal of Climatology 25 (10), 1345-1354, doi:10.1002/joc.1155.

Vinoth, J., Young, I., 2011. Global Estimates of Extreme Wind Speed and Wave Height. J Climate 24 (6), 1647-1665, doi:10.1175/2010JCLI3680.1.

von Storch, H., Zwiers, F., 1999. Statistical Analysis in Climate Research. Cambridge University Press.

Wang, X., Feng, Y., Swail, V., 2012. North Atlantic wave height trends as reconstructed from the 20th Century Reanalysis. Geophys Res Lett 39, L18705, 6 pp, doi:10.1029/2012GL053381, 2012GL053381.

Wang, X., Swail, V., 2001. Changes of extreme wave heights in Northern Hemisphere oceans and related atmospheric circulation regimes. J Climate 14 (10), 2204-2221, doi:10.1175/1520-0442(2001)014<2204:COEWHI>2.0.CO;2.

Wang, X., Swail, V., 2002. Trends of Atlantic wave extremes as simulated in a 40-yr wave hindcast using kinematically reanalyzed wind fields. J Climate 15 (9), 1020-1035, doi:10.1175/1520-0442(2002)015<1020:TOAWEA >2.0.CO;2.

Wang, X., Swail, V., 2006. Climate change signal and uncertainty in projections of ocean wave heights. Climate Dynamics 26 (2), 109-126, doi:10.1007/s00382-005-0080-x.

Wang, X., Zwiers, F., Swail, V., 2004. North Atlantic ocean wave climate change scenarios for the twenty-first century. J Climate 17 (12), 2368-2383, doi:10.1175/15200442(2004)017<2368:NAOWCC >2.0.CO;2.

Weisse, R., Günther, H., 2007. Wave climate and long-term changes for the Southern North Sea obtained from a high-resolution hindcast 1958-2002. Ocean Dynam 57 (3), 161-172, doi:10.1007/s10236-006-0094-x.

Wilks, D. S., 2006. Statistical Methods in the Atmospheric Sciences, 2nd ed. Academic Press.

World Meteorological Organization, 1998. Guide to wave analysis and forecasting. World Meteorological Organization, Geneva, Switzerland, 2nd Edition.

Young, I., Zieger, S., Babanin, A., 2011. Global trends in wind speed and wave height. Science 332 (6028), 451-455, doi:10.1126/science.1197219. 


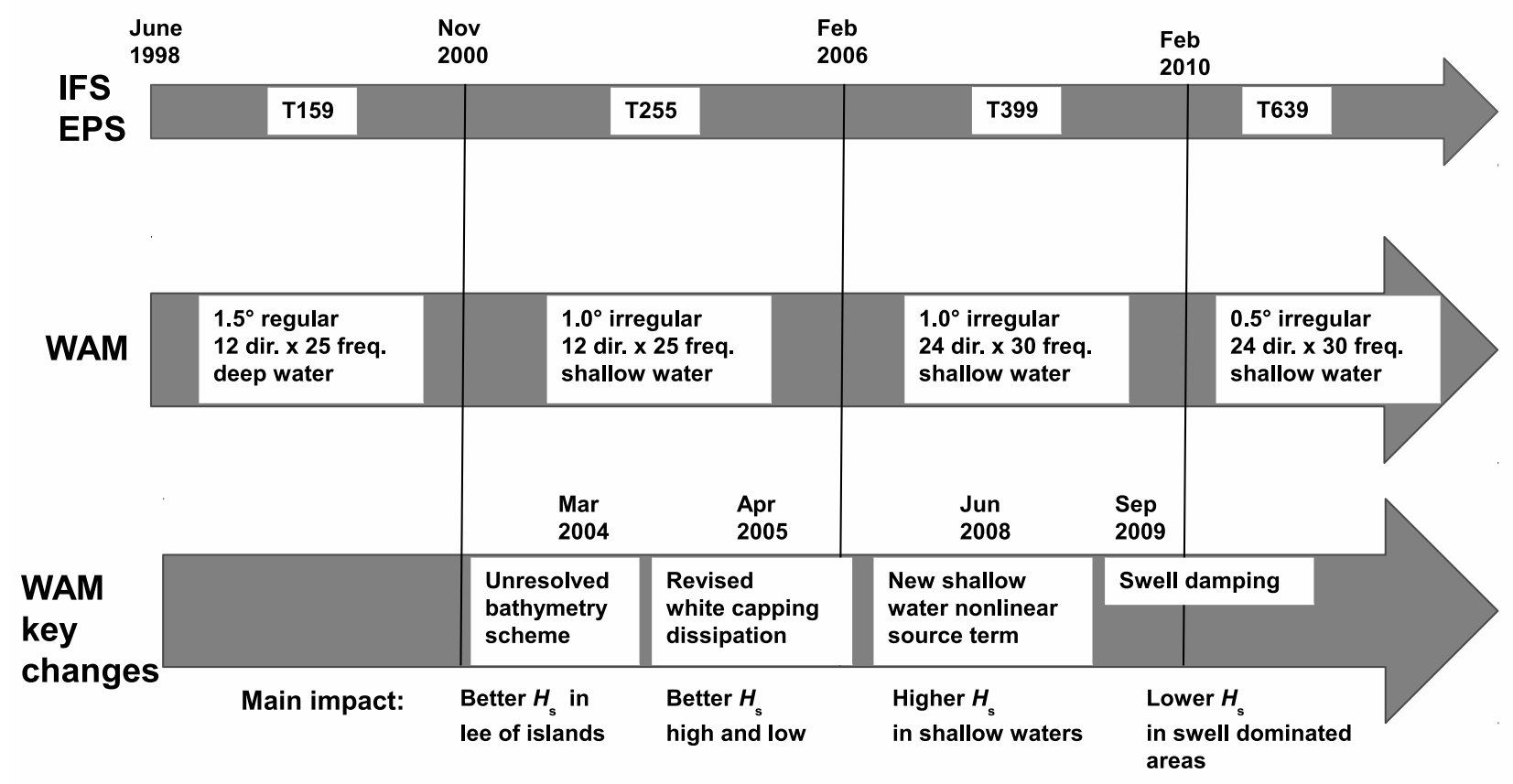

Figure 1: A timeline of major updates to the operational EPS. The upper arrow illustrates changes to the atmospheric component of the integrated forecast system (IFS) while the middle arrow lists the major changes to the wave model (WAM). Note that only one forecast per day (00 UTC) was issued before 2003-03-25. The most important changes related to the wave model are the changes in resolution which affect the areas in the lee of the Faroes and the introduction of shallow-water physics which mainly affects the southern North Sea. 


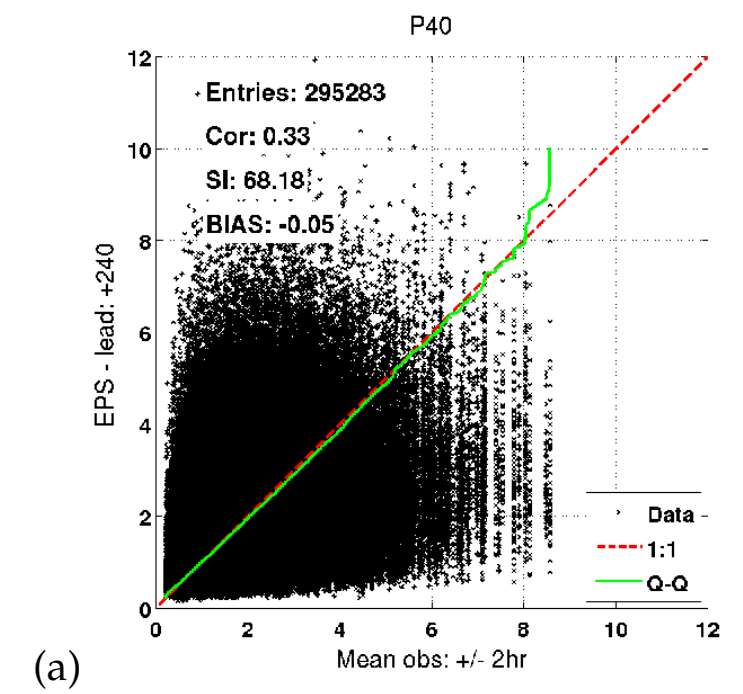

(a)
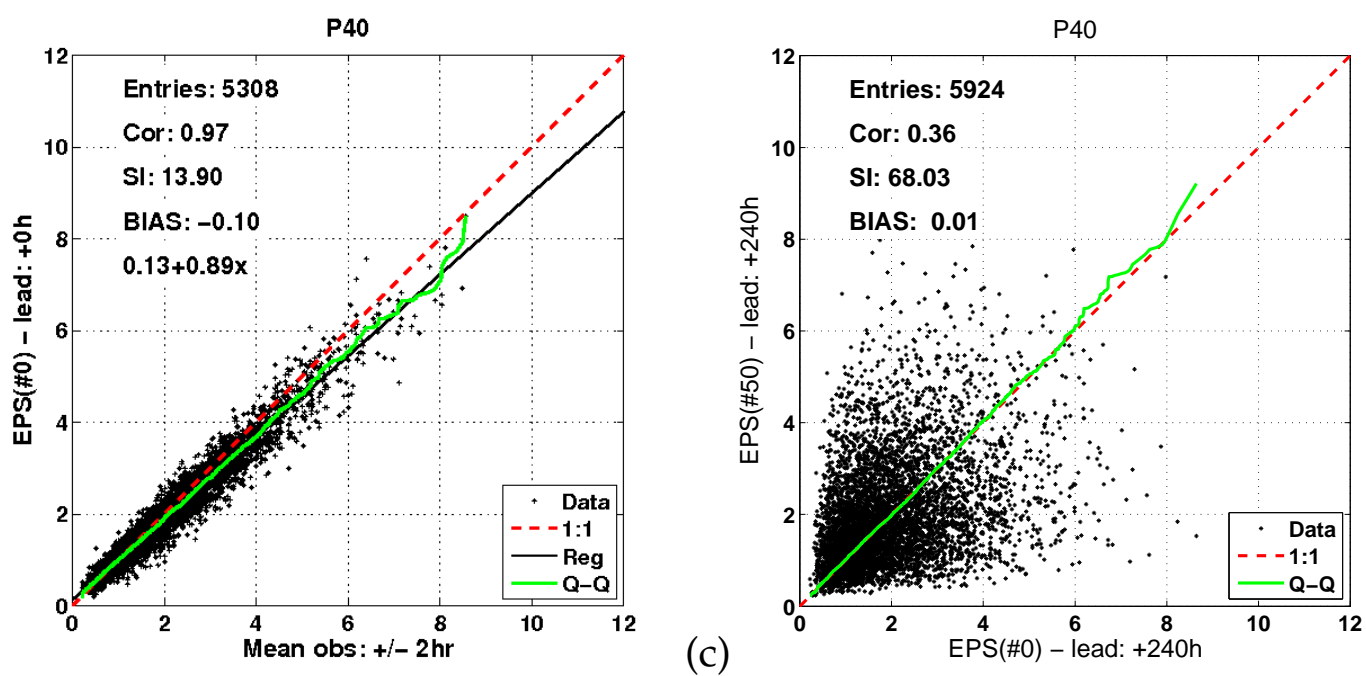

Figure 2: Panel a: The correlation of all 51 ensemble member forecasts at $+240 \mathrm{~h}$ with observations of significant wave height at location P40 (Ekofisk, central North Sea) over the whole period 1999-2009. The QQ curve is shown in green. It is clear that the $+240 \mathrm{~h}$ climate is quite similar to the observed climate in this location and better than the wave height distribution found at analysis time (b). Panel b: Same as panel (a) for analysis time. The EPS is biased low at analysis time. Panel c: The correlation between the $+240 \mathrm{~h}$ forecasts of two ensemble members (member 0 represents the unperturbed atmospheric integration) over the whole period 1999-2009. The QQ-curve is shown in green. The centered anomaly correlation relative to the weekly observed wave climate is 0.20 . 

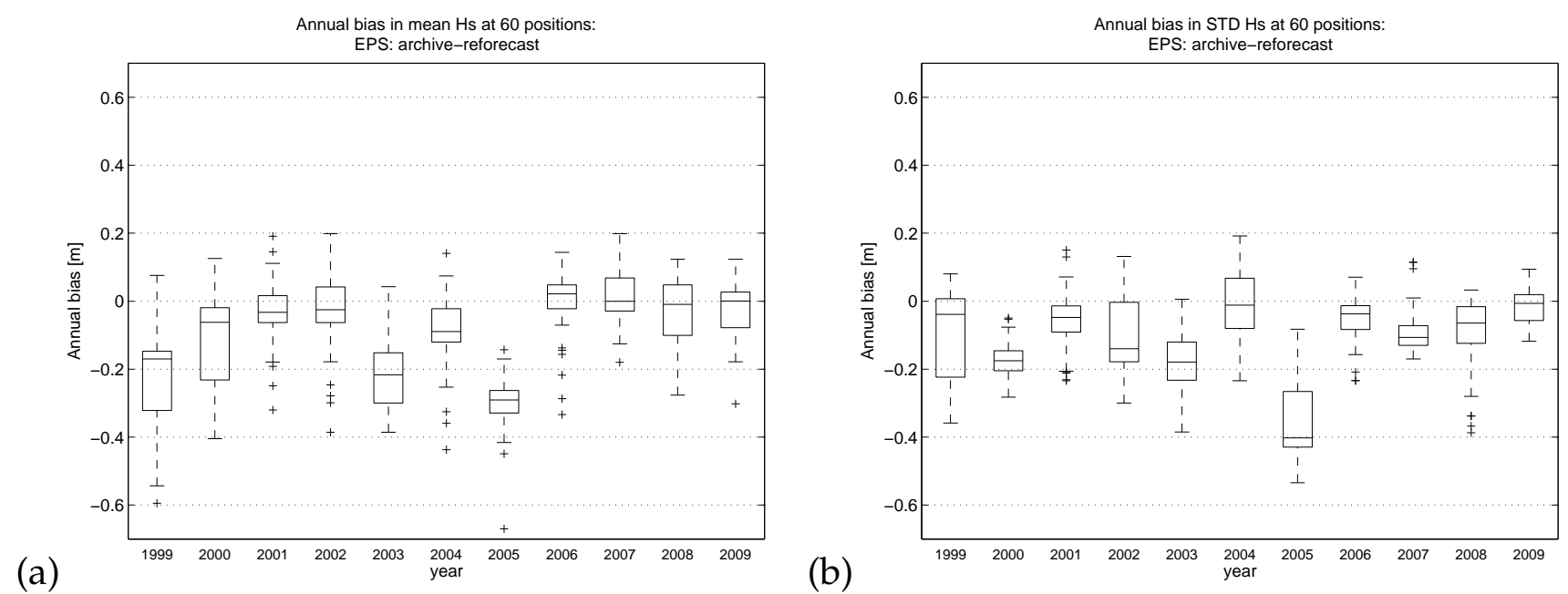

Figure 3: Panel a: Time series (1999-2009) of the difference in annual mean significant wave height $[\mathrm{m}]$ of EPS forecasts at lead time $+240 \mathrm{~h}$ and the reforecast at the same lead time from model cycle Cy36r4 (operational in May 2011) at 60 locations in the north-east Atlantic, the North Sea and the Norwegian Sea. Panel b: The difference in annual standard deviation [m] of the significant wave height of EPS240 and the reforecast. Considerable variations are found from one year to another, but no significant drift due to model upgrades is seen.

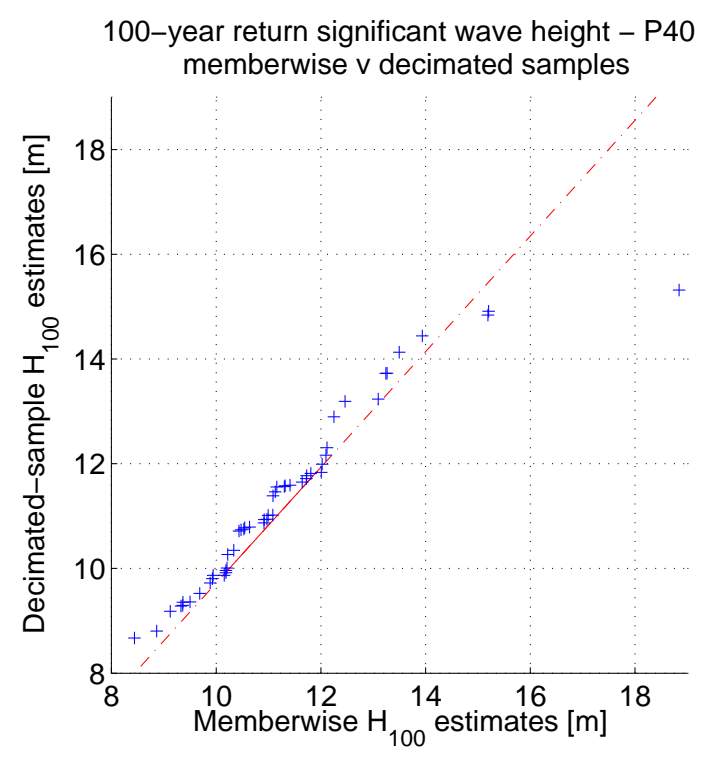

Figure 4: Comparison of the quantiles of $H_{100}$ (100-year return values) from 51 ensemble members over the whole period $1999-2009 \mathrm{v}$ the quantiles of $H_{100}$ estimates from 51 decimated samples of all ensemble members taken every 51 forecasts. This decimation gives 51 estimates of same sample size as the member-wise estimates. The distributions are very similar with common averages $(11.30 \mathrm{~m})$ and standard deviations of $1.83 \mathrm{~m}$ and $1.67 \mathrm{~m}$, respectively. 
(a)

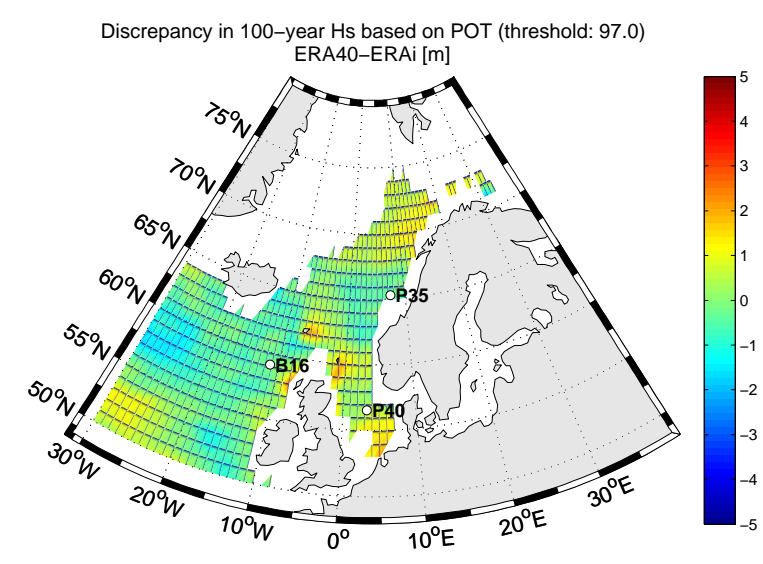

(b)

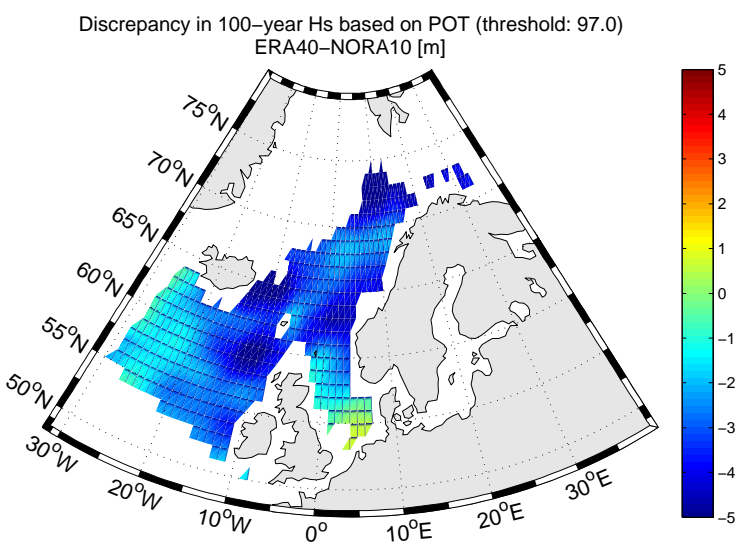

Figure 5: Panel a: Difference of $H_{100}$ of ERA-40 and ERA-I using the GP (POT) method with a threshold of $97 \%$. The differences are $\sim 1 \mathrm{~m}$ in the open ocean, but behind the Faroes and the Shetland isles ERA-40 yields higher return values. This is to be expected from a coarser reanalysis. The effect of the deep-water wave physics employed by the ERA-40 WAM model also yields higher return values in the North Sea. The model fields are interpolated to a common grid with $1.0^{\circ}$ resolution, and all ice-infested grid points have been excluded. The three buoy locations are marked as P40 (Ekofisk), B16 (K5) and P35 (Heidrun). Panel b: Difference of ERA-40 and NORA10, same threshold as for panel (a). The difference between NORA10 and ERA-40 is consistently $\sim 3 \mathrm{~m}$ in the open ocean, but approaches zero at the open boundary where ERA-40 provided the boundary values.

(a)

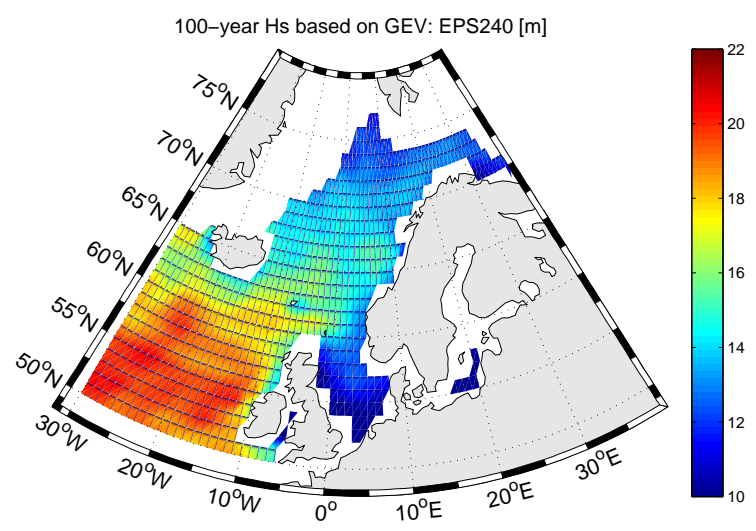

(b)

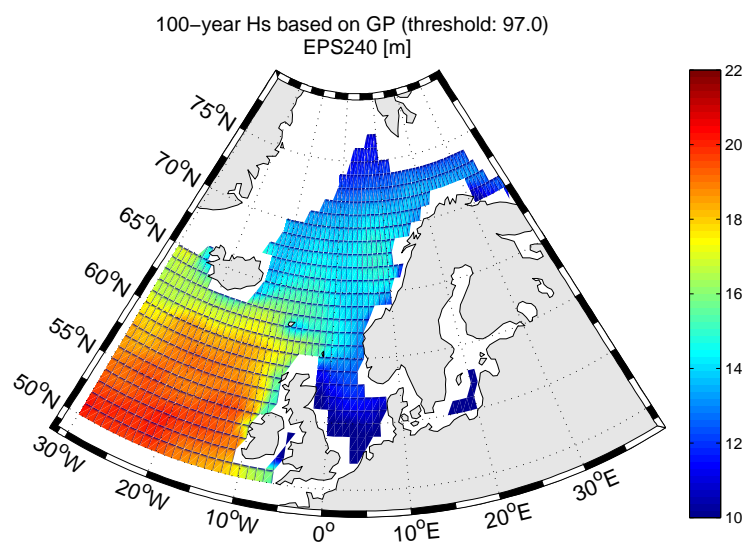

Figure 6: Panel a: Gridded estimates of $H_{100}$ from EPS240 using GEV with blocked maxima from individual ensemble members. The grid is $1.0^{\circ}$, and all ice-infested grid points have been excluded. Panel b: Same as panel (a) but for GP with a threshold of $97 \%$ of the data. 


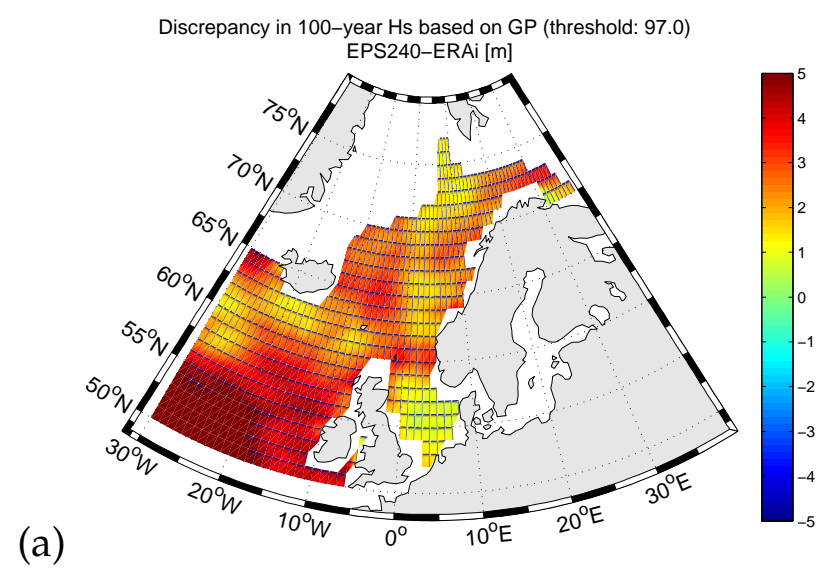

(b)

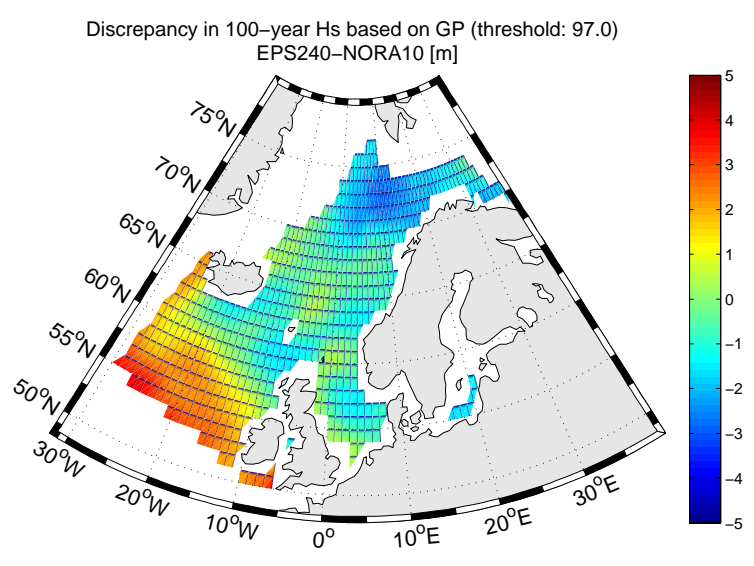

Figure 7: Panel a: Difference between $H_{100}$ estimates of EPS240 and ERA-I using the GP distribution with a threshold of 97\% (positive means EPS240 is higher). EPS240 consistently predicts higher return values throughout the domain. The differences are $\sim 3 \mathrm{~m}$ in the open ocean, with the North Atlantic approaching a difference of $5 \mathrm{~m}$. The differences are smallest in the central North Sea. The grid is $1.0^{\circ}$, and all ice-infested grid points have been excluded. Panel b: Difference between EPS240 and NORA10, same GP threshold as for panel (a). The difference between NORA10 and EPS240 is generally smaller than what was found in panel (a) for ERA-I, but significant geographical differences exist. Near the south-western boundary NORA10 is influenced by ERA-40, and behind the Faroe and Shetland archipelagos the resolution of EPS240 is too coarse to provide a meaningful comparison. 
(a)

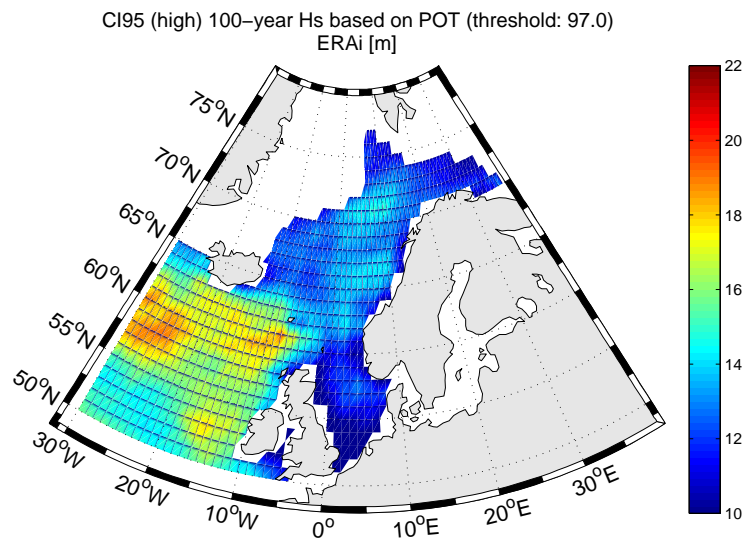

(c)

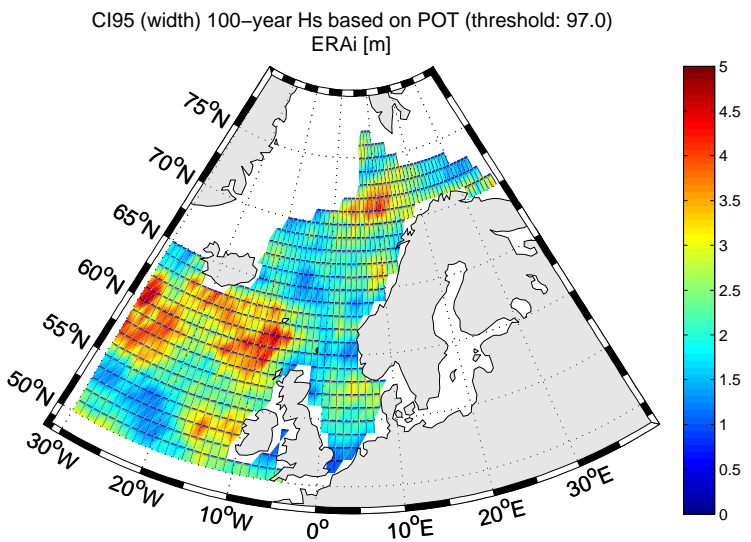

(b)

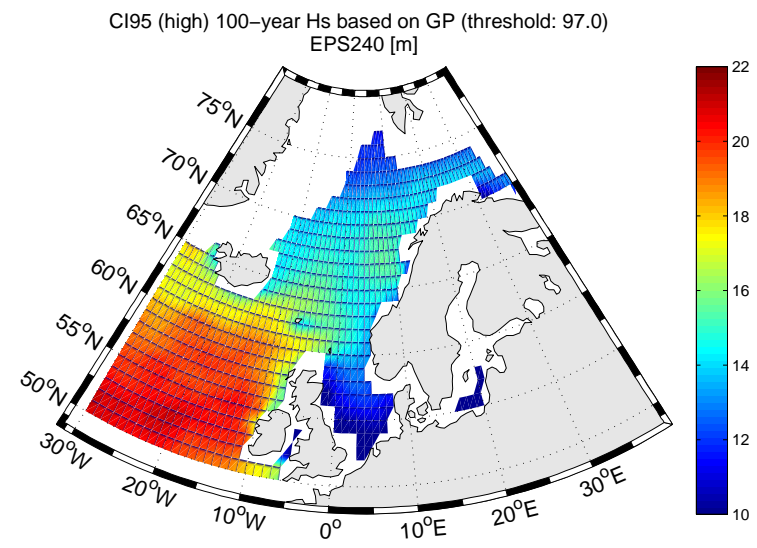

(d)

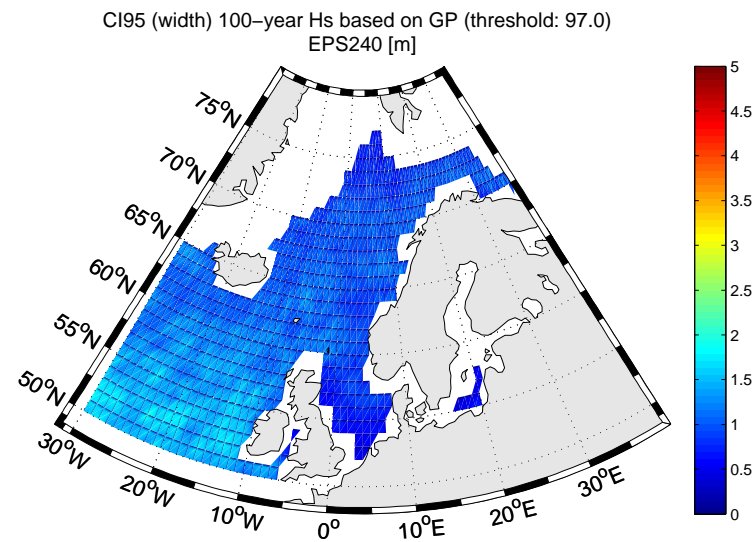

Figure 8: Panel a: Upper limit of 95\% confidence interval for ERA-I $H_{100}$ based on 100 bootstraps of the POT exceeding the 97 percentile. Panel b: Upper limit of 95\% confidence interval for EPS240 $\mathrm{H}_{100}$ based on 100 bootstraps of the data exceeding the 97 percentile. Panel c: Width of $95 \%$ confidence interval for ERA-I. The relative width reaches $30 \%$ of the return values in parts of the north-east Atlantic. The geographic variability is pronounced, largely due to influence from individual storm events. Panel d: Width of $95 \%$ confidence interval for EPS240. The relative width varies from 5\% in sheltered areas to $10 \%$ in the open ocean. The geographic variability is very low. 
(a)
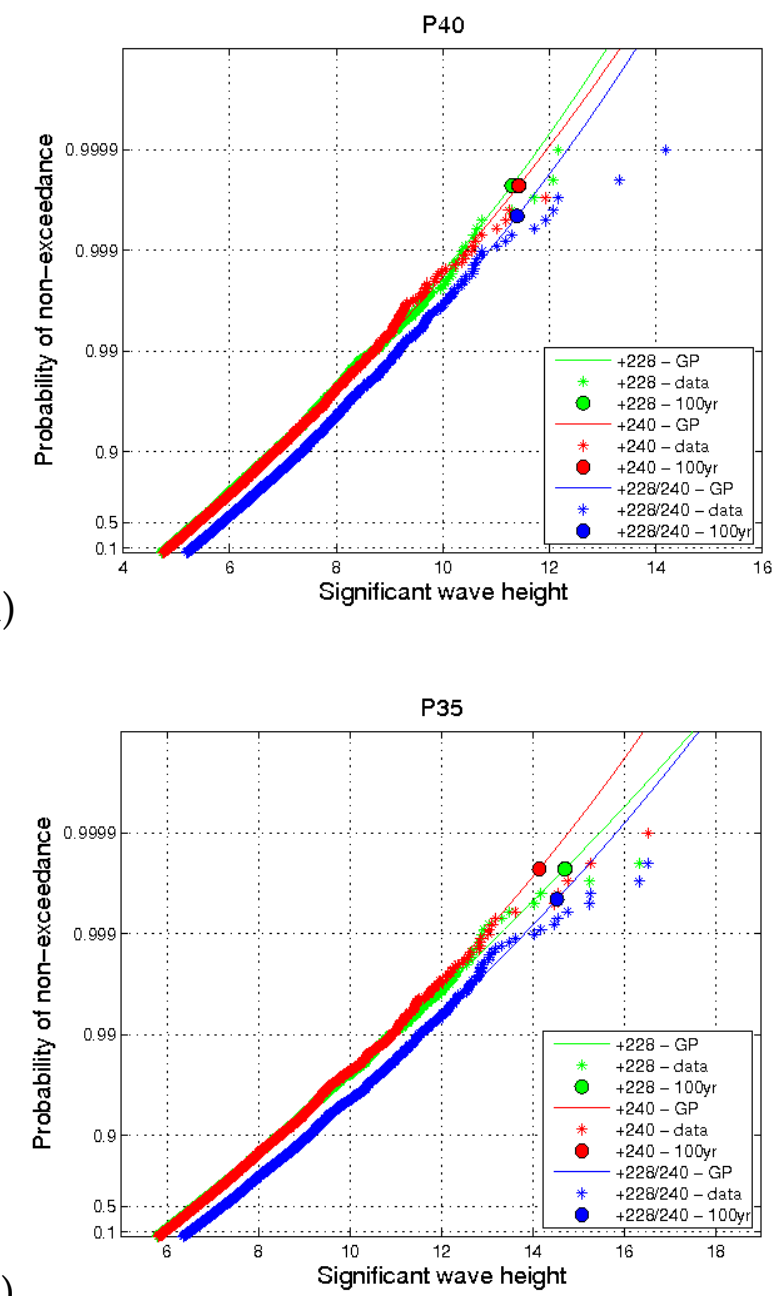

(b)

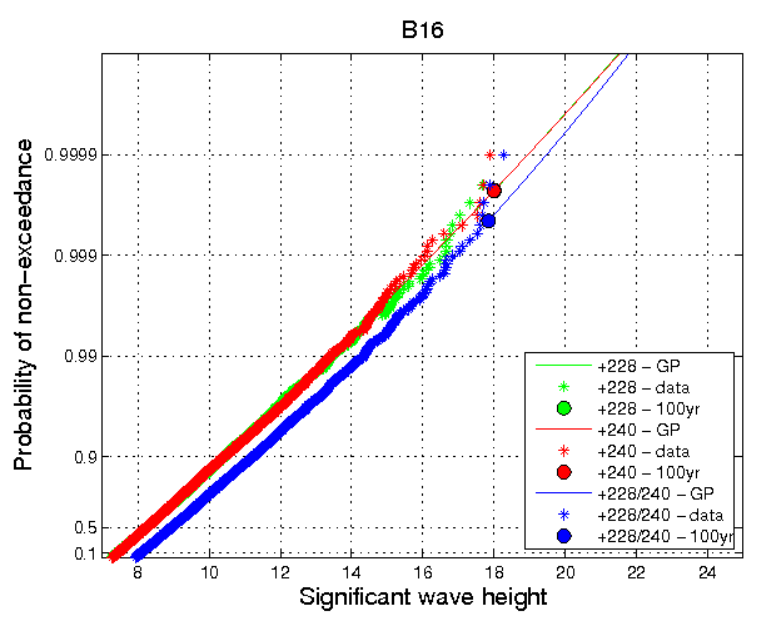

(c)

Figure 9: Panel a: Probability of non-exceedance for the EPS forecasts in location P40 (Ekofisk, central North Sea). The GPD estimates are shown as curves (with 100-year values marked as circles) and are based on a 97\% threshold while the individual forecast values are shown as asterisks. Green and red indicate EPS228 and EPS240, respectively. Blue is a combined estimate for EPS228 and EPS240 where the maximum of each pair of EPS228 and EPS240 forcast is chosen. This is done because the two forecasts are separated by only $12 \mathrm{~h}$ and strongly correlated. The combined data set thus represents the equivalent of 452 years of data since EPS228 and EPS240 each represents the equivalent of 226 years. The combined data set lies below the EPS228 and EPS240 on the vertical axis since it has a lower probability of non-exceedance due to being twice the size of EPS228 and EPS240. Panel b: Same as panel (a) but for location B16 in the eastern North Atlantic (note that the upper three values of EPS228 are masked by EPS240 as the values are almost identical. Panel c: Same as panel (a) but for location P35 in the eastern Norwegian Sea (Heidrun). It is evident from all three panels that the combined 100-year estimate is bracketed by the estimates from the two individual estimates, as expected from a larger dataset. 


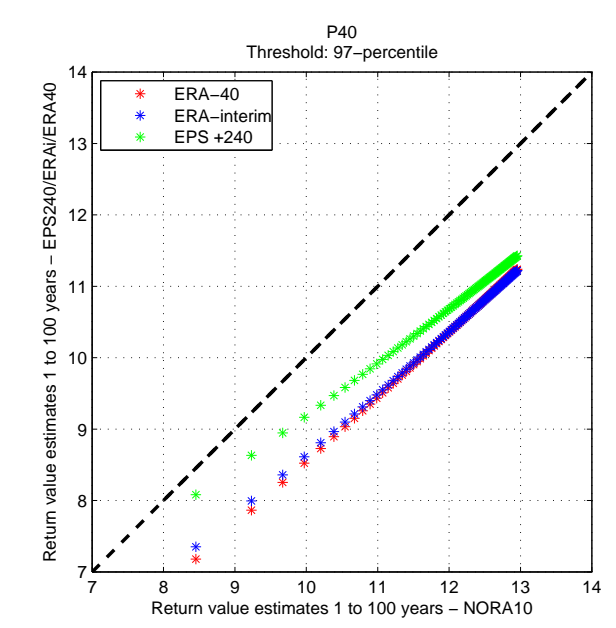

(a)

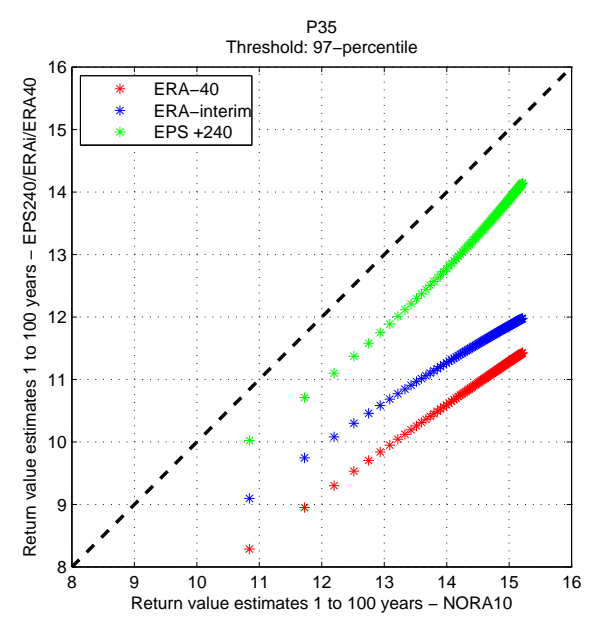

(b)

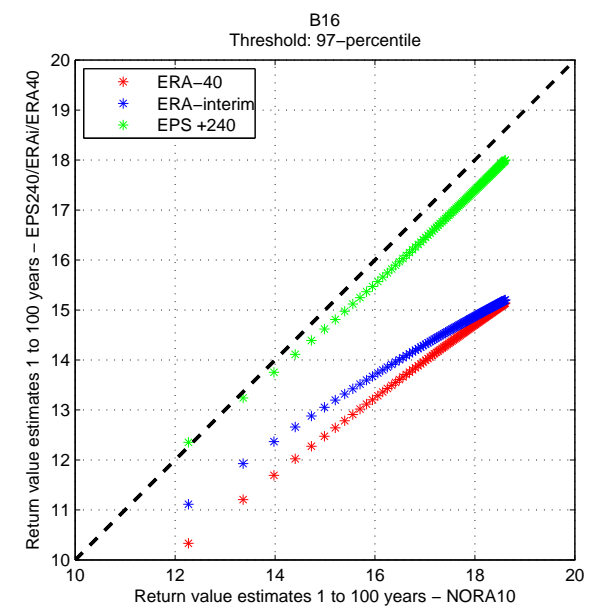

(c)

Figure 10: Panel a. "Comet plot" comparison of $H_{1}, H_{2}, \ldots, H_{100}$ return values in the central North Sea (P40, Ekofisk) for NORA10 (first axis) against ERA-40 (red asterisks), ERA-I (blue) and EPS240 (green). All return estimates were made from the GP distribution with a 97\% threshold. Panel b. Same as panel (a) but for location B16 in the eastern North Atlantic. Panel c. Same as panel (a) but for location P35 in the eastern Norwegian Sea (Heidrun). ERA-40 and ERA-I estimates are significantly lower than NORA10 in all three locations. EPS240 shows good correspondence in open-ocean conditions over the whole range up to $H_{100}$ (panels b and c), while in the North Sea the upper return values are substantially lower and closer to the ERA-40 and ERA-I estimates. 